\title{
Multiple relapses of Plasmodium vivax malaria acquired from West Africa and association with poor metabolizer CYP2D6 variant: a case report
}

\author{
Xi He ${ }^{1}$, Maohua Pan², Weilin Zeng ${ }^{1}$, Chunyan Zou ${ }^{3}$ Liang Pi', Yucheng Qin², Luyi Zhao', Pien Qin², Yuxin Lu², \\ J. Kevin Baird ${ }^{5,6}$, Yaming Huang ${ }^{1,4 \dagger}$, Liwang Cui $^{7^{*+}}$ (D) and Zhaoqing Yang ${ }^{1+}$
}

\begin{abstract}
Background: Plasmodium vivax transmission in West Africa, dominant for the Duffy-negative blood group, has been increasingly recognized from both local residents as well as international travelers who contracted $P$. vivax malaria there. However, the relapsing pattern and sensitivity to antimalarial treatment of $P$. vivax strains originated from this region are largely unknown. There is evidence that the efficacy of primaquine for radical cure of relapsing malaria depends on host factors such as the hepatic enzyme cytochrome P450 (CYP) 2 D6.

Case presentation: A 49-year-old Chinese man was admitted to the Shanglin County Hospital in Guangxi Province, China, on December 19, 2016, 39 days after he returned from Ghana, where he stayed for one and a half years. He was diagnosed by microscopy as having uncomplicated $P$. vivax malaria. Treatment included 3 days of intravenous artesunate (420 mg total), and 3 days of chloroquine (1550 $\mathrm{mg}$ total), and 8 days of primaquine (180 $\mathrm{mg}$ total). Although parasites and symptoms were cleared rapidly and he was malaria-negative for almost two months, he suffered four relapses with relapse intervals ranging from 58 to 232 days. The last relapse occurred at 491 days from his first vivax attack. For the first three relapses, he was treated similarly with chloroquine and primaquine, sometimes supplemented with additional artemisinin combination therapies (ACTs). For the last relapse, he was treated with intravenous artesunate, 3 days of an ACT, and 7 days of azithromycin, and had remained healthy for 330 days. Molecular studies confirmed $P$. vivax infections for all the episodes. Although this patient was diagnosed to have normal glucose-6-phosphate dehydrogenase (G6PD) activity, his CYP2D6 genotype corresponded to a ${ }^{*} 2 \mathrm{~A} /{ }^{*} 36$ allele variant suggesting of an impaired primaquine metabolizer phenotype.

Conclusions: This clinical case suggests that $P$. vivax malaria originating from West Africa may produce multiple relapses extending beyond one year. The failures of primaquine as an anti-relapse therapy may be attributed to the patient's impaired metabolizer phenotype of the CYP2D6. This highlights the importance of knowing the host G6PD and CYP2D6 activities for effective radical cure of relapsing malaria by primaquine.
\end{abstract}

Keywords: Plasmodium vivax, West Africa, Relapse pattern, Primaquine failure, CYP2D6

\footnotetext{
* Correspondence: Icui@health.usf.edu

†Yaming Huang, Liwang Cui and Zhaoqing Yang contributed equally to this work.

${ }^{7}$ Department of Internal Medicine, Morsani College of Medicine, University of South Florida, 3720 Spectrum Blvd, Suite 304, Tampa, FL 33612, USA

Full list of author information is available at the end of the article
}

C The Author(s). 2019 Open Access This article is distributed under the terms of the Creative Commons Attribution 4.0 International License (http://creativecommons.org/licenses/by/4.0/), which permits unrestricted use, distribution, and reproduction in any medium, provided you give appropriate credit to the original author(s) and the source, provide a link to the Creative Commons license, and indicate if changes were made. The Creative Commons Public Domain Dedication waiver (http://creativecommons.org/publicdomain/zero/1.0/) applies to the data made available in this article, unless otherwise stated. 


\section{Background}

Plasmodium vivax is geographically the most widely distributed malaria parasite, and was responsible for about 14.3 million malaria cases in 2017 in the world [1]. Malaria in Southeast Asia and South America is dominated by $P$. vivax; in Africa, $P$. vivax is much less common than the overwhelming number of $P$. falciparum cases. Historically, it has been considered extremely rare or "absent" in Central and West Africa because of the dominance of the Duffy-negative blood group, which was regarded as a receptor required for the invasion of the erythrocytes by $P$. vivax [2]. In recent years, there is growing evidence documenting $P$. vivax infections in local residents of Central and West Africa as well as international travelers returning from the regions to malaria-free countries $[3,4]$. In China, for example, of the 909 imported P. vivax cases in 2012, 122 originated in 21 Central and West African countries [5]. These records provide compelling evidence of widespread $P$. vivax transmission in Africa. Notably, the identification of $P$. vivax strains able to infect Duffynegative individuals [6-8] demonstrates that Duffy negativity is not a definitive barrier to vivax transmission. In addition, the presence of very few Duffy-positive hosts in these populations may be enough to sustain low-level transmission of $P$. vivax malaria in these regions. The considerable number of vivax cases routinely diagnosed among Duffy-positive international travelers acquired in West and Central Africa implies hidden local transmission of $P$. vivax malaria in these regions despite predominance of Duffy negativity.

Historically, $P$. vivax malaria has been called a "benign tertian malaria," but this is a misnomer, given that recent studies have demonstrated severe and fatal pathologies associated with $P$. vivax malaria $[9,10]$. Relapses caused by the liver hypnozoites of this parasite can occur months or even several years after the primary attack, thereby contributing to additional morbidity and potentially onward transmission that impedes malaria elimination. In Papua New Guinea, it was estimated that $80 \%$ of acute incident vivax infections was derived from relapses rather than new mosquito-borne infections [11].

In most $P$. vivax-endemic areas, chloroquine/primaquine $(\mathrm{CQ} / \mathrm{PQ})$, offering blood schizontocidal and hypnozoitocidal therapy, has been used for more than 60 years and remains the frontline radical cure for uncomplicated vivax cases in most regions (excepting Southeast Asia where resistance to chloroquine commonly occurs) [12]. The standard treatment regimen includes three days of CQ (total $25 \mathrm{mg} / \mathrm{kg}$ ) plus fourteen daily dosages of PQ $(0.25 \mathrm{mg} / \mathrm{kg})$. However, PQ imposes a serious problem of toxicity in patients with glucose-6-phosphate dehydrogenase (G6PD) deficiency, an X-linked enzymopathy that can be highly prevalent in endemic areas. As a result, without testing G6PD status of the patients, health providers often do not offer PQ for fear of potentially severe hemolysis. When PQ is prescribed without direct supervision, adherence to the 14-day regimen is poor [13]. To improve adherence, China recommends a shorter 8 -day course of PQ regimen $(0.375 \mathrm{mg} / \mathrm{kg} /$ day; total dose of $3.0 \mathrm{mg} / \mathrm{kg}$ ) for relapsing malaria (http:// www.chinacdc.cn/tzgg/201109/t20110906_52137.htm). Although the 8-day PQ regimen has not been rigorously tested in clinical trials, earlier studies indicate that the temperate $P$. vivax strains from Korea are completely susceptible to a total dose of $3.5 \mathrm{mg} / \mathrm{kg}$ [14].

Another problem that affects the effectiveness of $P Q$ for radical cure of vivax malaria involves the host hepatic enzyme cytochrome P450 (CYP) 2D6 [15], which mediates activation of PQ to its active metabolite(s) $[16,17]$. CYP2D6 is involved in the metabolism of $>20 \%$ prescribed medicine. It is noteworthy that CYP2D6 is the member of the CYP450 family having the greatest genetic polymorphism [18, 19]. The frequencies of alleles with reduced function are as high as $50 \%$ in some Asian populations [20], although contributions of different CYP2D6 alleles to PQ failures still need to be firmly established [21, 22]. In clinical trials to assess the effectiveness of PQ for preventing relapses, even under directly observed high-dose PQ therapy, as many as $13.9 \%$ P. vivax patients experienced relapses [23, 24]. Using genotyping and dextromethorphan metabolism phenotyping of CYP2D6 polymorphism in those subjects, Baird et al. documented almost all of those treatment failures to be associated with impaired CYP2D6 function [25].

Here we describe multiple relapses of a case of vivax malaria acquired in West Africa that also appears to be associated with impaired CYP2D6 metabolism of PQ.

\section{Case presentation \\ Case}

A 49-year-old man who had experienced fever and chills for half a day was admitted to the Shanglin County Hospital in Guangxi Province, China, on December 19, 2016. He showed additional symptoms including headache, body aches and cough (Table 1). Upon inquiry of travel history, he informed the doctor that he had spent one year and three months in Ghana (8/15/2015-11/10/ 2016) and returned home 39 days ago. He explained that during his stay in Ghana, he had experienced two episodes of malaria (species unknown); his last episode of malaria was about half a year ago and both times he was self-treated with artemisinin drugs. On admission, he weighed of $70.2 \mathrm{~kg}$, his axillary temperature was $38.0^{\circ} \mathrm{C}$, and his heart rate, blood pressure and respiratory rate were 92 beats/min, $91 / 60 \mathrm{mmHg}$ and 20 breaths $/ \mathrm{min}$, respectively. With his recent travel history, venous blood 
Table 1 The timeline of the $P$. vivax attacks for the patient and antimalarial treatment

\begin{tabular}{|c|c|c|c|c|c|}
\hline & 1st attack & 2nd attack & 3rd attack & 4th attack & 5th attack \\
\hline Days from previous attack & 0 & 58 & 113 & 88 & 232 \\
\hline Days from the 1st attack & 0 & 58 & 171 & 259 & 491 \\
\hline $\begin{array}{l}\text { Axillary temperature }\left({ }^{\circ} \mathrm{C}\right) \text { on } \\
\text { admission }\end{array}$ & 38.0 & 38.3 & 38.4 & 38.6 & 38.9 \\
\hline Symptoms ${ }^{a}$ & $\mathrm{R}, \mathrm{H}, \mathrm{B}, \mathrm{C}$ & $\mathrm{R}, \mathrm{H}, \mathrm{B}$ & $\mathrm{R}, \mathrm{H}, \mathrm{B}$ & $\mathrm{R}, \mathrm{H}, \mathrm{B}$ & $R, H, B$ \\
\hline Parasitemia (\%) on admission & 0.36 & 0.25 & 0.19 & 0.18 & 0.38 \\
\hline Treatment $^{\mathrm{b}}$ & $\begin{array}{l}\mathrm{CQ} / \mathrm{PQ}+\mathrm{AS}(420 \\
\mathrm{mg})\end{array}$ & $\begin{array}{l}\mathrm{CQ} / \mathrm{PQ}+\mathrm{AS}(660 \mathrm{mg}) \\
\mathrm{ACT} 1\end{array}$ & $\begin{array}{l}\mathrm{CQ} / \mathrm{PQ}+\mathrm{AS}(660 \mathrm{mg}) \\
\mathrm{ACT} 2\end{array}$ & $\begin{array}{l}\mathrm{CQ} / \mathrm{PQ} \\
\mathrm{ACT} 2\end{array}$ & $\begin{array}{l}\text { AS ( } 660 \mathrm{mg})+ \text { AZ (3500 mg); } \\
\text { ACT2 }\end{array}$ \\
\hline Fever clearance time $(h)$ & 16 & 21 & 18.5 & NA & 23 \\
\hline
\end{tabular}

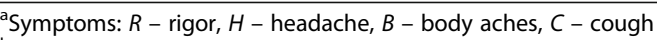

${ }^{b}$ Drug treatment: $C Q / P Q$ - chloroquine (total $1200 \mathrm{mg}$ base, $600 \mathrm{mg}$ on day $1,300 \mathrm{mg}$ each on day 2 and 3)/primaquine (total $180 \mathrm{mg}, 22.5 \mathrm{mg}$ daily for 8 days), $A S$ - artesunate at $12 \mathrm{~h}$ interval, $A C T 1$ - artesunate-amodiaquine, $A C T 2$ - dihydroartemisinin-piperaquine, $A Z$ - azithromycin, NA - not available

was drawn for general hematology and blood chemistry analyses, and a drop of the blood was used to make a thin smear for malaria diagnosis by microscopy. Microscopic examination of the Giemsa-stained blood smear revealed $P$. vivax parasites. Blood tests showed increases in white blood cells $\left(14.25 \times 10^{9} / \mathrm{L}\right.$; reference range 4$\left.10 \times 10^{9}\right)$, neutrophil ratio $(85.0 \% ; 43-76 \%)$, and C-reactive protein $(142.29 \mathrm{mg} / \mathrm{L})$. He was conscious and oriented to time, place, and person. He was not dehydrated, pale, or in respiratory distress. Since he did not have any severe symptoms, he was diagnosed as having uncomplicated vivax malaria. He spent three days in the county hospital and was given three days of oral CQ therapy (total $1550 \mathrm{mg}$ ). To help resolve the symptoms faster, he was also given intravenous (IV) injections of artesunate (total dose of $420 \mathrm{mg}$, initial dose of $120 \mathrm{mg}$, subsequently divided into 5 times of $60 \mathrm{mg}$ at a $12 \mathrm{~h}$ interval). Meanwhile, after confirming that he is G6PD normal, an 8-day course of PQ ( $22.5 \mathrm{mg} /$ day) was begun. Fever was cleared within one day and parasitemia was cleared within two days. The patient was discharged on day four with instructions for follow-up visits if symptoms reappear. Administration of the remaining five days of PQ was directly observed therapy (DOT) by local Center for Disease Control (CDC) personnel to ensure compliance.

The second attack of febrile paroxysm occurred 58 days later on February 15, 2017, and he was admitted to the county hospital again with similar symptoms as the first attack and diagnosed with $P$. vivax malaria by microscopy (Table 1). The patient had not left Guanxi Province during the 58 days between these two attacks. He was hospitalized for six days and was treated with the same CQ/PQ combination, together with eleven IV injections of artesunate (total dose of $660 \mathrm{mg}$ at an interval of $12 \mathrm{~h}$ ). Given that the doctor was not sure whether this re-occurrence was due to chloroquine resistance or potential mixed infection with $P$. falciparum, at discharge he was given additional three days of an artemisinin-based combination therapy (ACT), artesunate-amodiaquine, which has a different aminoquinoline drug. Both ACT and PQ were administered as DOT by local CDC staff.

One hundred and thirteen days later, on June 8, 2017, he suffered a third attack of confirmed $P$. vivax malaria and hospitalized at the county hospital for six days. $\mathrm{He}$ received the same therapy as for the second attack including DOT of 8-day PQ. At home, he was further treated with three days of a different ACT, dihydroartemisinin-piperaquine.

Eighty-eight days later, on September 4, 2017, he suffered a fourth attack of confirmed vivax malaria. This time he was not hospitalized, while the same CQ/PQ regimen together with three days of oral therapy of dihydroartemisinin-piperaquine was prescribed. All treatments were taken at home and supervised by local CDC staff.

Despite the fact that, after returning from Ghana, this patient lived the entire time in a malaria-free area, he had the fifth attack of vivax malaria 232 days later, on April 24, 2018, 491 days from the first attack. He was admitted to the county hospital for three days and was given IV injection of artesunate six times at a $12 \mathrm{~h}$ interval $(120 \mathrm{mg}$ each at the first three injections, and $60 \mathrm{mg}$ each at the three subsequent injections). PQ was not prescribed since it was judged not effective. Instead, he was treated with azithromycin $(500 \mathrm{mg} /$ day) for seven days. At discharge, he was also given three additional days of dihydroartemisinin-piperaquine. At the time of this interview, he had remained healthy for 330 days after this last episode of vivax malaria.

\section{Laboratory studies}

Venous blood was collected at the time of diagnosis at the first, second, third, and fifth attacks. Blood samples were used for molecular diagnosis and genotyping at the Kunming Medical University laboratory. For each sample, total DNA was extracted from $0.2 \mathrm{~mL}$ of venous 
blood using the High Pure PCR Template Preparation Kit (Roche, Switzerland) following the manufacturer's instruction and eluted in $100 \mu \mathrm{l}$ of water. Plasmodium species were identified by nested PCR targeting the $18 \mathrm{~S}$ rRNA genes using genus-specific and species-specific primers for $P$. falciparum, $P$. vivax, $P$. malariae and $P$. ovale [26]. The PCR results showed that all the samples were positive only for $P$. vivax (data not shown).

To determine whether the relapses were caused by different parasite strains, we genotyped the polymorphic $P$. vivax merozoite surface protein (PvMSP) $3 \alpha$ gene by the nested PCR and restriction fragment length polymorphism (PCR/RFLP) methods described earlier [27]. PCR of $P v M S P 3 \alpha$ alone detected a similar band size for the first three attacks, but the PCR product from the fifth attack was smaller (Fig. 1a). Digestion of the $P v M S P 3 \alpha$ by HhaI showed the same restriction patterns for the first three attacks, whereas the fifth attack was clearly different, suggesting that the first three attacks were likely due to the same parasite strain, whereas the last attack was from a different parasite strain (Fig. 1b).

Since the effectiveness of PQ for radical cure of vivax malaria is influenced by host CYP2D6 activity, we wanted to determine whether the failure of PQ in this case might be linked to CYP2D6 genotypes suggestive of poor metabolizer of $\mathrm{PQ}$. The single nucleotide polymorphisms (SNPs) in CYP2D6 were determined by PCR amplification of the full-length CYP2D6 coding region using a high-fidelity enzyme and sequencing of the PCR products, similar to a method described earlier [28]. Primary PCR was performed using primers P1 (5'CTGGCAGCACAGTCAACA-3') and P2 (5' ${ }^{\prime}$ TTTGTC TTCCGTTTTGGG-3'), while nested reactions were done with primers $\mathrm{N} 1$ (5'-ATAAGGGAAGGGTCAC GC-3') and N2 (5'-GGCAAGGGTAACTGACATCT$\left.3^{\prime}\right)$. The following PCR conditions were used: initial denaturing at $95^{\circ} \mathrm{C}$ for $3 \mathrm{~min}, 35$ cycles of $95^{\circ} \mathrm{C}$ for $15 \mathrm{~s}$, $53^{\circ} \mathrm{C}\left(58^{\circ} \mathrm{C}\right.$ for nested reactions) for $15 \mathrm{~s}$, and $72^{\circ} \mathrm{C}$ for $5 \mathrm{~min}$, and final extension at $72^{\circ} \mathrm{C}$ for $5 \mathrm{~min}$. PCR and sequencing of CYP2D6 detected mutations 214G $>C$, $221 \mathrm{C}>\mathrm{A}, \quad 223 \mathrm{C}>\mathrm{G}, \quad 227 \mathrm{~T}>\mathrm{C}, \quad 232 \mathrm{G}>\mathrm{C}, \quad 233 \mathrm{~A}>\mathrm{C}$, $245 \mathrm{~A}>\mathrm{G}, 310 \mathrm{G}>\mathrm{T}, 745 \mathrm{C}>\mathrm{G}, 842 \mathrm{~T}>\mathrm{G}, 1662 \mathrm{G}>\mathrm{C}$, $2851 \mathrm{C}>\mathrm{T}, 3385 \mathrm{~A}>\mathrm{C}, 3585 \mathrm{G}>\mathrm{A}, 3791 \mathrm{C}>\mathrm{T}, 4181 \mathrm{G}>\mathrm{C}$, and $4482 \mathrm{G}>\mathrm{A}$, which are classified as $* 2 \mathrm{~A}$, and mutations $100 \mathrm{C}>\mathrm{T}, 310 \mathrm{G}>\mathrm{T}, \quad 842 \mathrm{~T}>\mathrm{G}, 1038 \mathrm{C}>\mathrm{T}, 1662 \mathrm{G}>\mathrm{C}$, 2098A $>$ G, 3385A $>$ C, 3583A $>$ G, 4125G $>C, 4129 C>G$, $4132 \mathrm{~A}>\mathrm{G}, 4134 \mathrm{~T}>\mathrm{C}, 4156 \mathrm{C}>\mathrm{T}, 4157 \mathrm{~A}>\mathrm{C}, 4159 \mathrm{G}>\mathrm{C}$, $4165 \mathrm{~T}>\mathrm{G}, 4167 \mathrm{~T}>\mathrm{C}, 4168 \mathrm{G}>\mathrm{A}, 4169 \mathrm{C}>\mathrm{G}, 4170 \mathrm{~T}>\mathrm{C}$, $4173 \mathrm{C}>\mathrm{T}$, and $4181 \mathrm{G}>\mathrm{C}$, which are classified as $* 36$. According to the CYP2D6 allele naming database (www. Pharmvar.org/gene/CYP2D6), the patient's CYP2D6 genotype corresponds to a *2A/*36 allele variant. CYP2D6*2A is predicted to be functionally normal (score 1 ), but $* 36$ is non-functional (score 0 ). Thus, the overall genotype activity

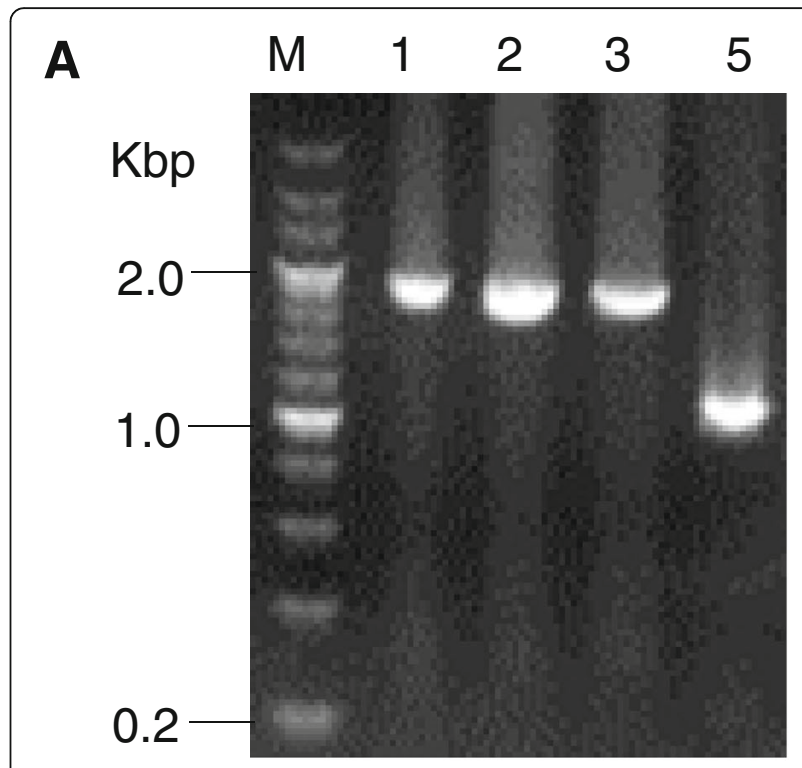

B

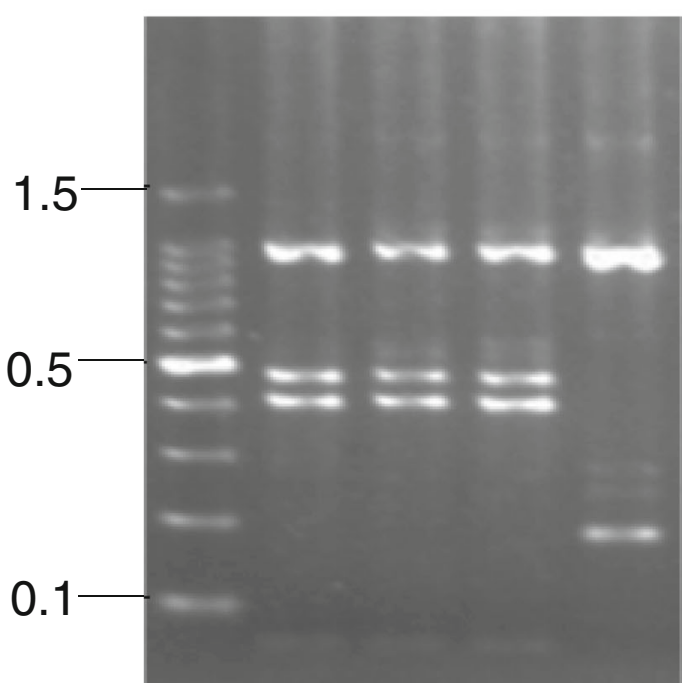

Fig. 1 Genotyping of $P$. vivax parasites in primary and subsequent attacks of the same patient. a Nested PCR analysis of PVMSP3a gene from the primary $P$. vivax infection (lane 1 ) and subsequent relapses (lanes 2, 3, and 5). b Restriction digestion of the nested PCR products shown in panel A by Hhal. $M$, molecular marker in Kbp

score was 1 , suggesting that this patient's CYP2D6 was an impaired PQ metabolizer phenotype [21]. Real-time PCR was performed to determine the CYP2D6 gene copy number using a previously described method [29], and the result showed that CYP2D6 gene in this patient was a single copy.

\section{Discussion and conclusions}

We documented a $P$. vivax infection acquired in West Africa producing four relapses with the last relapse occurring at 491 days after the first attack. This study suggests that although vivax malaria is considered to be 
exceedingly rare in West Africa because of predominance of Duffy-negativity in the local human population, there is a considerable hazard for Duffy-positive travelers to acquire relapsing malaria parasites in this region. This malaria case provides evidence indicating that $P$. vivax strains from West Africa may produce multiple relapses extending beyond one year but less than two. The relapse patterns of $P$. vivax strains from different geographical regions can vary significantly, from the tropical 'frequent-relapse phenotype' to the temperate "long-latency" phenotype' [30]. The relapse intervals of this Western African strain ranged from 58 days to 232 days. This is quite different from the relapsing patterns of $P$. vivax strains from the tropical Pacific region such as the Chesson strain, which relapse quickly but typically do not extend beyond one year [30]. This patient stayed the entire time after returning from Ghana in Guangxi, a malaria-free area after 2012 [31], thus the possibility of new infections was highly improbable but could not be ruled out since Guangxi borders with Vietnam and Yunnan, where very lowlevel transmission of $P$. vivax occurred. Furthermore, genotyping of the parasites by PCR-RFLP of $P v M s p 3 a$ gene indicates that the first two relapses had the same genotype as the primary infection, although the parasite from the fourth relapse had a different genotype. This suggests that the initial inoculum might include more than one strain of $P$. vivax as sporozoites from one oocyst in the mosquito may comprise sibling progeny of a single gametocyte mating event, or that he had multiple infections during his stay in Ghana. It is not uncommon that relapses and primary infections are genotypically different and relapses often result from activation of heterologous hypnozoites [32, 33].

Despite the fact that this Chinese patient received PQ treatment each time he had acute $P$. vivax infection, PQ therapy failed to prevent subsequent relapses. The excessive blood schizonticides given to this patient were not rational and did not prevent relapses. There are a number of possible reasons for the PQ treatment failures. One possibility is that the 8-day PQ treatment is able to prevent relapses for the temperate $P$. vivax strain [34] and the subtropical strains [35] in China, but may be ineffective against West African P. vivax. It is noteworthy that although the daily adult dose for the 8-day PQ regimen $(22.5 \mathrm{mg})$ is higher than for the standard 14-day regimen $(15 \mathrm{mg} /$ day $)$, the total PQ dosage for the 8 -day course $(180 \mathrm{mg})$ is lower than for the 14-day course $(210 \mathrm{mg})$. In addition, since the 8 -day PQ regimen $(0.375 \mathrm{mg} / \mathrm{kg} /$ day $)$ is calculated for adults weighing 60 $\mathrm{kg}$, this patient was also slightly under-dosed $(0.32 \mathrm{mg} /$ $\mathrm{kg} /$ day). Currently, there are no clinical studies testing the effectiveness of PQ treatment against relapses of
West African $P$. vivax strains. In Shanglin County Hospital, of 105 P. vivax patients who received the 8-day PQ regimen between 2013 and May 2019, four patients (3.8\%) had relapses, suggesting that the 8-day PQ regimen worked at least partially for preventing relapses of P. vivax parasites. Another possibility for the $\mathrm{PQ}$ failure lies in the patient's CYP2D6 enzyme, which is known to metabolize PQ to its active metabolite(s) for the hypnozoitocidal activity of PQ [16]. This patient has a CYP2D6 *2A/*36 genotype, which corresponds to being an impaired PQ metabolizer phenotype. CYP2D6 intermediate and poor metabolizer phenotypes have been linked to poor treatment outcome of PQ anti-relapse therapy in clinical trials $[15,25]$. Subjects with an activity score phenotype of 1.0 for CYP2D6 have shown variable responsiveness to $\mathrm{PQ}$ therapy against relapse of $P$. vivax; among the 7 patients evaluated by Bennett et al., none relapsed, whereas among the 22 patients evaluated by Baird et al., 12 relapsed [15, 25]. Although our patient may seem to have been administered a normally inadequate regimen of primaquine, he received it four times delivering a total dose of $720 \mathrm{mg}(10.3 \mathrm{mg} / \mathrm{kg})$ that failed to prevent relapse. Interestingly, a case report showed that repeated relapses of vivax malaria acquired in Papua New Guinea also were likely attributed to the patient's intermediate metabolizer phenotype of the CYP2D6 allele $(* 5 / * 41)$ [36]. The current case of $P$. vivax malaria acquired in West Africa adds further support to the importance of the CYP2D6 polymorphisms for the effectiveness of the PQ anti-relapse therapy. With the demonstrated efficacy of a single-dose tafenoquine in preventing relapses of vivax malaria [37] and the seemingly lack of effects of CYP2D6 on tafenoquine [38], tafenoquine may be the choice of anti-relapse medicine in G6PD normal patients. It nonetheless remains uncertain whether tafenoquine is CYP2D6dependent or not.

\section{Abbreviations \\ ACT: Artemisinin-based combination therapy; CDC: Center for Disease Control; CQ: Chloroquine; CYP: Cytochrome P450; DOT: Directly observed therapy; G6PD: Glucose-6-phosphate dehydrogenase; IV: Intravenous; PQ: Primaquine; RFLP: Restriction fragment length polymorphism}

\section{Acknowledgements}

We want to thank the staff at the Shanglin Hospital for collecting data on hematology and blood chemistry for the vivax patient, and local CDC personnel for the directly observed therapy.

\section{Authors' contributions}

$X H, W Z, L P$, and LZ: Molecular diagnosis, designing, writing and editing of manuscript. MP, CZ, YQ, PQ, YL and $Y H$ : Diagnosis and management of patient and editing of manuscript; and JKB, YH, LC and ZY: Overall coordination, study design, writing and revision of manuscript. All authors read and approved the final manuscript. 


\section{Funding}

This study was supported by the National Institute of Allergy and Infectious Diseases, National Institutes of Health USA (U19A1089672). ZY was supported by grants (31860604 and U1802286) from the National Natural Science Foundation of China and by a grant (2018ZF0081) from Major Science and Technology Projects of Yunnan. CZ was funded by a grant from the Youth Fund Project of People's Hospital of Guangxi Zhuang Autonomous Region, China (QN2017-10). MP was funded by a grant (ZC20153012) from the Science and Technology Bureau Programs of Nanning, Guangxi, China. The funding bodies had no role in design of the study, analysis and interpretation of the data, and writing of the manuscript.

\section{Availability of data and materials}

All relevant data and materials are included in the manuscript.

\section{Ethics approval and consent to participate}

The clinical study of malaria involving human subjects was approved by the Institutional Review Board of Kunming Medical University IRB\#KMC2012-01, KMC2017-01). Written informed consent was obtained from the patient.

\section{Consent for publication}

Written informed consent for publication of clinical details was obtained from the patient.

\section{Competing interests}

The authors declare that they have no competing interests.

\section{Author details}

'Department of Pathogen Biology and Immunology, Kunming Medical University, Kunming, Yunnan 650500, People's Republic of China. ${ }^{2}$ Shanglin County People's Hospital, Shanglin, Guangxi 530500, People's Republic of China. ${ }^{3}$ Guangxi Zhuang Autonomous Region People's Hospital, Nanning, Guangxi 530021, People's Republic of China. ${ }^{4}$ Guangxi Zhuang Autonomous Region Center for Disease Prevention and Control, Nanning, Guangxi 530021, People's Republic of China. ${ }^{5}$ Eijkman-Oxford Clinical Research Unit, Jalan Diponegoro No. 69, Jakarta 10430, Indonesia. ${ }^{6}$ Centre for Tropical Medicine and Global Health, Nuffield Department of Medicine, University of Oxford, Old Road Campus, Roosevelt Drive, Oxford OX3 7FZ, UK. ${ }^{7}$ Department of Internal Medicine, Morsani College of Medicine, University of South Florida, 3720 Spectrum Blvd, Suite 304, Tampa, FL 33612, USA.

Received: 2 May 2019 Accepted: 5 August 2019

\section{Published online: 09 August 2019}

\section{References}

1. Battle KE, Lucas TCD, Nguyen M, Howes RE, Nandi A. Mapping the global endemicity and clinical burden of Plasmodium vivax in 2017. Lancet. 394(10195):2019, 332-343.

2. Miller LH, Mason SJ, Clyde DF, McGinniss MH. The resistance factor to Plasmodium vivax in blacks. The Duffy-blood-group genotype, FyFy. N Engl J Med. 1976;295(6):302-4

3. Howes RE, Reiner RC Jr, Battle KE, Longbottom J, Mappin B, Ordanovich D, Tatem AJ, Drakeley C, Gething PW, Zimmerman PA, et al. Plasmodium vivax transmission in Africa. PLoS Negl Trop Dis. 2015;9(11):e0004222.

4. Twohig KA, Pfeffer DA, Baird JK, Price RN, Zimmerman PA, Hay SI, Gething PW, Battle KE, Howes RE. Growing evidence of Plasmodium vivax across malaria-endemic Africa. PLoS Negl Trop Dis. 2019;13(1):e0007140.

5. Feng J, Xiao H, Zhang L, Yan H, Feng X, Fang W, Xia Z. The Plasmodium vivax in China: decreased in local cases but increased imported cases from Southeast Asia and Africa. Sci Rep. 2015;5:8847.

6. Menard D, Barnadas C, Bouchier C, Henry-Halldin C, Gray LR, Ratsimbasoa A, Thonier V, Carod JF, Domarle O, Colin Y, et al. Plasmodium vivax clinical malaria is commonly observed in Duffy-negative Malagasy people. Proc Natl Acad Sci U S A. 2010;107(13):5967-71.

7. Russo G, Faggioni G, Paganotti GM, Djeunang Dongho GB, Pomponi A, De Santis R, Tebano G, Mbida M, Sanou Sobze M, Vullo V, et al. Molecular evidence of Plasmodium vivax infection in Duffy negative symptomatic individuals from Dschang, West Cameroon. Malar J. 2017;16(1):74.

8. Ngassa Mbenda HG, Das A. Molecular evidence of Plasmodium vivax mono and mixed malaria parasite infections in Duffy-negative native Cameroonians. PLoS One. 2014;9(8):e103262.
9. Anstey NM, Russell B, Yeo TW, Price RN. The pathophysiology of vivax malaria. Trends Parasitol. 2009;25(5):220-7.

10. Baird JK. Evidence and implications of mortality associated with acute Plasmodium vivax malaria. Clin Microbiol Rev. 2013;26(1):36-57.

11. Robinson $\sqcup$, Wampfler R, Betuela I, Karl S, White MT, Li Wai Suen CS, Hofmann NE, Kinboro B, Waltmann A, Brewster J, et al. Strategies for understanding and reducing the Plasmodium vivax and Plasmodium ovale hypnozoite reservoir in Papua new Guinean children: a randomised placebo-controlled trial and mathematical model. PLoS Med. 2015;12(10):e1001891.

12. Price RN, von Seidlein L, Valecha N, Nosten F, Baird JK, White NJ. Global extent of chloroquine-resistant Plasmodium vivax: a systematic review and meta-analysis. Lancet Infect Dis. 2014;14(10):982-91.

13. Khantikul N, Butraporn P, Kim HS, Leemingsawat S, Tempongko MA, Suwonkerd W. Adherence to antimalarial drug therapy among vivax malaria patients in northern Thailand. J Health Popul Nutr. 2009;27(1):4-13.

14. Baird JK, Hoffman SL. Primaquine therapy for malaria. Clin Infect Dis. 2004;39(9):1336-45.

15. Bennett JW, Pybus BS, Yadava A, Tosh D, Sousa JC, McCarthy WF, Deye G, Melendez V, Ockenhouse CF. Primaquine failure and cytochrome P-450 2D6 in Plasmodium vivax malaria. N Engl J Med. 2013;369(14):1381-2.

16. Pybus BS, Marcsisin SR, Jin X, Deye G, Sousa JC, Li Q, Caridha D, Zeng Q, Reichard GA, Ockenhouse $C$, et al. The metabolism of primaquine to its active metabolite is dependent on CYP 2D6. Malar J. 2013;12:212.

17. Pybus BS, Sousa JC, Jin X, Ferguson JA, Christian RE, Barnhart R, Vuong C, Sciotti RJ, Reichard GA, Kozar MP, et al. CYP450 phenotyping and accurate mass identification of metabolites of the 8-aminoquinoline, anti-malarial drug primaquine. Malar J. 2012;11:259.

18. Zhou SF, Liu JP, Lai XS. Substrate specificity, inhibitors and regulation of human cytochrome P450 2D6 and implications in drug development. Curr Med Chem. 2009;16(21):2661-805.

19. Zhou SF. Polymorphism of human cytochrome P450 2D6 and its clinical significance: part I. Clin Pharmacokinet. 2009;48(11):689-723.

20. Bradford LD. CYP2D6 allele frequency in European Caucasians, Asians, Africans and their descendants. Pharmacogenomics. 2002;3(2):229-43.

21. Baird JK, Battle KE, Howes RE. Primaquine ineligibility in anti-relapse therapy of Plasmodium vivax malaria: the problem of G6PD deficiency and cytochrome P-450 2D6 polymorphisms. Malar J. 2018;17(1):42.

22. Chen N, Dowd S, Gatton ML, Auliff A, Edstein MD, Cheng Q. Cytochrome P450 2D6 profiles and their relationship with outcomes of primaquine antirelapse therapy in Australian Defence force personnel deployed to Papua New Guinea and East Timor. Malar J. 2019;18(1):140.

23. Sutanto I, Tjahjono B, Basri H, Taylor WR, Putri FA, Meilia RA, Setiabudy R, Nurleila S, Ekawati LL, Elyazar I, et al. Randomized, open-label trial of primaquine against vivax malaria relapse in Indonesia. Antimicrob Agents Chemother. 2013;57(3):1128-35.

24. Nelwan EJ, Ekawati LL, Tjahjono B, Setiabudy R, Sutanto I, Chand K, Ekasari T, Djoko D, Basri H, Taylor WR, et al. Randomized trial of primaquine hypnozoitocidal efficacy when administered with artemisinin-combined blood schizontocides for radical cure of Plasmodium vivax in Indonesia. BMC Med. 2015;13(1):294.

25. Baird JK, Louisa M, Noviyanti R, Ekawati L, Elyazar I, Subekti D, Chand K, Gayatri A. Instiaty, Soebianto $S$ et al: association of impaired cytochrome P450 2D6 activity genotype and phenotype with therapeutic efficacy of Primaquine treatment for latent Plasmodium vivax malaria. JAMA Netw Open. 2018;1(4):e181449.

26. Johnston SP, Pieniazek NJ, Xayavong MV, Slemenda SB, Wilkins PP, da Silva AJ. PCR as a confirmatory technique for laboratory diagnosis of malaria. J Clin Microbiol. 2006;44(3):1087-9.

27. Bruce MC, Galinski MR, Barnwell JW, Snounou G, Day KP. Polymorphism at the merozoite surface protein-3alpha locus of Plasmodium vivax: global and local diversity. Am J Trop Med Hyg. 1999;61(4):518-25.

28. Puaprasert K, Chu C, Saralamba N, Day NPJ, Nosten F, White NJ, Dondorp AM, Imwong M. Real time PCR detection of common CYP2D6 genetic variants and its application in a Karen population study. Malar J. 2018;17(1):427.

29. Gaedigk A, Twist GP, Leeder JS. CYP2D6, SULT1A1 and UGT2B17 copy number variation: quantitative detection by multiplex PCR. Pharmacogenomics. 2012;13(1):91-111.

30. White NJ, Imwong M. Relapse. Adv Parasitol. 2012;80:113-50. 
31. Li J, Yang Y, Zhang W, Wei S, Lin K. Mid-term assessment report of malaria elimination action plan in Guangxi. China Trop Med. 2016;16(4):305-10.

32. Chen N, Auliff A, Rieckmann K, Gatton M, Cheng Q. Relapses of Plasmodium vivax infection result from clonal hypnozoites activated at predetermined intervals. J Infect Dis. 2007;195(7):934-41.

33. Imwong M, Snounou G, Pukrittayakamee S, Tanomsing N, Kim JR, Nandy A, Guthmann JP, Nosten F, Carlton J, Looareesuwan S, et al. Relapses of Plasmodium vivax infection usually result from activation of heterologous hypnozoites. J Infect Dis. 2007;195(7):927-33.

34. Hsiang MS, Hwang J, Tao AR, Liu Y, Bennett A, Shanks GD, Cao J, Kachur SP, Feachem RG, Gosling RD, et al. Mass drug administration for the control and elimination of Plasmodium vivax malaria: an ecological study from Jiangsu Province, China. Malaria J. 2013;12:383.

35. Liu H, Yang HL, Xu JW, Wang JZ, Nie RH, Li CF. Artemisinin-naphthoquine combination versus chloroquine-primaquine to treat vivax malaria: an openlabel randomized and non-inferiority trial in Yunnan Province, China. Malaria journal. 2013:12:409.

36. Ingram RJ, Crenna-Darusallam C, Soebianto S, Noviyanti R, Baird JK. The clinical and public health problem of relapse despite primaquine therapy: case review of repeated relapses of Plasmodium vivax acquired in Papua New Guinea. Malar J. 2014;13:488.

37. Lacerda MVG, Llanos-Cuentas A, Krudsood S, Lon C, Saunders DL, Mohammed R, Yilma D, Batista Pereira D, Espino FEJ, Mia RZ, et al. Singledose Tafenoquine to prevent relapse of Plasmodium vivax malaria. N Engl J Med. 2019;380(3):215-28.

38. St Jean PL, Xue Z, Carter N, Koh GC, Duparc S, Taylor M, Beaumont C, Llanos-Cuentas A, Rueangweerayut R, Krudsood S, et al. Tafenoquine treatment of Plasmodium vivax malaria: suggestive evidence that CYP2D6 reduced metabolism is not associated with relapse in the phase $2 \mathrm{~b}$ DETECTIVE trial. Malar J. 2016;15(1):97.

\section{Publisher's Note}

Springer Nature remains neutral with regard to jurisdictional claims in published maps and institutional affiliations.

Ready to submit your research? Choose BMC and benefit from:

- fast, convenient online submission

- thorough peer review by experienced researchers in your field

- rapid publication on acceptance

- support for research data, including large and complex data types

- gold Open Access which fosters wider collaboration and increased citations

- maximum visibility for your research: over $100 \mathrm{M}$ website views per year

At $\mathrm{BMC}$, research is always in progress.

Learn more biomedcentral.com/submissions 